Case Report

\title{
Coexistence of Emphysematous Pyelonephritis and Cystitis in a Patient with COVID-19 Complicated with Spontaneous Pneumomediastinum
}

\author{
Ibrahim Boukhannous $\mathbb{D}^{1},{ }^{1}$ Anouar El Moudane $\mathbb{D}^{1},{ }^{1}$ Mehdi Chennoufi ${ }^{10},{ }^{1}$ \\ Mohamed Mokhtari, ${ }^{1}$ Abdelghani Ouraghi $\mathbb{D}^{1},{ }^{1}$ Hamza Mimouni $\mathbb{D}^{2},{ }^{2}$ and Ali Barki $\mathbb{D}^{1}$ \\ ${ }^{1}$ Department of Urology, Mohamed VI University Hospital Center, Mohamed I University, Oujda, Morocco \\ ${ }^{2}$ Department of Anesthesia and Intensive Care, Mohamed VI University Hospital Center, Mohamed I University, Oujda, Morocco
}

Correspondence should be addressed to Ibrahim Boukhannous; boukhannous.1@gmail.com

Received 18 May 2021; Accepted 17 September 2021; Published 5 October 2021

Academic Editor: Salim Surani

Copyright ( 2021 Ibrahim Boukhannous et al. This is an open access article distributed under the Creative Commons Attribution License, which permits unrestricted use, distribution, and reproduction in any medium, provided the original work is properly cited.

\begin{abstract}
We report the first case of a 52-year-old nondiabetic male admitted for management of uremic syndrome associated with emphysematous pyelonephritis (EPN), renal and perinephric abscess, and emphysematous cystitis (EC) on a single functional kidney with a large abundance of spontaneous pneumomediastinum (SP) complicating a SARS-CoV-2 pneumonia. The patient has benefited from several dialysis sessions, intravenous antibiotics, and percutaneous drainage. His clinical course was complicated by acute respiratory distress syndrome, and unfortunately, he died nine days following admission.
\end{abstract}

\section{Introduction}

Since the first case of COVID-19, no EPN and EC associated with SARS-CoV-2 pneumonia was reported, with only a few spontaneous pneumomediastinums reported in the literature. Here, we report the first association of these rare entities.

EPN is a necrotizing infection with gas presence in the renal parenchyma, collecting system, or perinephric tissues [1]. Meanwhile, EC is defined by the presence of gas inside and around the bladder wall produced by bacterial or fungal fermentation [2].

On the other hand, spontaneous pneumomediastinum in the SARS-CoV-2 pneumonia is a rare complication, defined by the presence of air in the mediastinum apart from any invasive or noninvasive positive pressure ventilation. Its pathophysiology is still poorly understood.

\section{Case Report}

A 52-year-old patient with no previous history was admitted to the emergency room for the management of acute renal failure with uremic syndrome. The clinical examination found a conscious patient, hemodynamically and respiratory stable, hypertensive at $190 / 100 \mathrm{mmgh}$, and febrile at $39^{\circ} \mathrm{C}$ with generalized abdominal defense, with a preserved diuresis. The admission assessment showed a creatinine level at $169 \mathrm{mg} / \mathrm{l}$, a urea level at $4.75 \mathrm{~g} / \mathrm{l}, \mathrm{K}+$ at $5.2 \mathrm{mmol} / \mathrm{L}, \mathrm{Na}$ at $132 \mathrm{mmol} / \mathrm{L}, \mathrm{Ca}$ at $91 \mathrm{mg} / \mathrm{L}, \mathrm{CRP}$ at $240 \mathrm{mg} / \mathrm{L}$, a white blood cell count at 12190 per microliter, hypochromic microcytic anemia at $8.5 \mathrm{~g} / \mathrm{dL}$, leukocyturia at 11860000 per microliter, and hematuria at 315000 per microliter.

An abdominal CT scan was carried out as part of the aetiological assessment objectified right kidney atrophy, and a left kidney sits with calyceal dilation upstream of a pyelic 
lithiasis of $29 \times 21 \mathrm{~mm}$ density $500 \mathrm{HU}$ with bubbles of intracaliceal air complicated by a collection under the left renal capsule, well limited, hypodense containing air bubbles, with enhanced thin wall after injection of contrast product, communicating with intraperitoneal collections at the level of the left iliac fossa, the left parietocolic groove, and the peripancreatic and periduodenal hypochondrium measuring approximately $208 \times 113 \mathrm{~mm}$ with air bubbles at the level of the bladder. The high digestive opacification does not show any passage of the contrast product intraperitoneally (Figures 1(a)-1(d)).

The patient received 4 dialysis sessions, probabilistic antibiotic therapy based on ceftriaxone for 48 hours with adaptation by imipenem after ECBU result returning in favor of multidrug-resistant Pseudomonas aeruginosa. Furthermore, percutaneous drainage of the collection with a left double J stent placement with bladder irrigation was performed. The course was marked by the disappearance of the fever on the 4 th day after admission and an improvement in the infectious assessment and renal function.

However, on the 7 th day, the patient presented with chest pain and respiratory distress made up of polypnea with an $84 \%$ desaturation requiring an increase in $\mathrm{O} 2$ intakes to $15 \mathrm{l} / \mathrm{min}$ with the mask at high concentration. After stabilization of the patient, a thoracic CT angiography was performed objectifying ground-glass opacities with crazy paving of mixed topography, bilateral to lower predominance with a degree of critical involvement $>75 \%$ classified CORADS 5 and a large abundance of pneumomediastinum with no sign of pulmonary embolism (Figures 2(a)-2(c)). A PCR test is made positive. The patient was placed on Claforan $1 \mathrm{~g} / 8 \mathrm{~h}$, dexamethasone $6 \mathrm{mg} / \mathrm{d}$, Rovamycin $3 \mathrm{MI} / 8 \mathrm{~h}$, Lovenox $4000 \mathrm{IU} / \mathrm{d}$, paracetamol $1 \mathrm{~g} / 8 \mathrm{~h}$, and omeprazole $40 \mathrm{mg} / \mathrm{d}$.

Faced with no respiratory improvement, the patient was transferred to intensive care. The blood gas analysis found a hypoxic patient, $\mathrm{pH}$ at $7.34, \mathrm{PaO} 2$ at $52 \mathrm{mmHg}, \mathrm{PaCO} 2$ at $32 \mathrm{mmHg}$, and bicarbonate at $30 \mathrm{mmol} / \mathrm{l}$, initially put on Optiflow with $\mathrm{FiO} 2$ at $100 \%$. Saturation improved to $92 \%$.

Six hours after his admission to intensive care, a worsening of the polypnea with signs of respiratory struggles and thoracoabdominal swaying set in with $82 \%$ desaturation under Optiflow, hence the indication of protective ventilation intubation with tidal volume at $10 \mathrm{PEP}, \mathrm{FR}$ at 20 cycles/minute, and $\mathrm{FiO} 2$ at $70 \%$ with sedation by Diprivan $120 \mathrm{mg} / \mathrm{h}$, Sufenta $15 \mathrm{gamma} / \mathrm{h}$, and Atacurium $50 \mathrm{mg} / \mathrm{h}$.

The course was marked by the cardiorespiratory arrest on D2 of hospitalization in intensive care following refractory hypoxia.

\section{Discussion}

The mortality rate of EPN or EC is between 8.7 and $21 \%$. It is a life-threatening infection on its own $[1,3]$. Several risk factors were associated with a higher mortality rate, such as shock condition, urgent hemodialysis, severe hypoalbuminemia, inappropriate antibiotic therapy, and polymicrobial infections [4].
Usually, it affects diabetic patients, which is not the case with this patient. Moreover, the high urinary sugar level provides a favorable environment for urinary-onset sepsis development, especially EPN, EC, renal, and perirenal abscess, which is already very rare [5]. Our patient is the first to have grouped this rare combination with SARS-CoV-2 pneumonia complicated by a large abundance of SP.

Based on the CT scan data, there are two classifications of EPN in the literature, Huang et al. and Wan et al.'s classifications [6].

Huang et al.'s classification proposed 4 classes:

(i) Class 1: emphysematous pyelitis

(ii) Class 2: gas in the renal parenchyma without extension to the extrarenal space

(iii) Class 3A: extension of the gas or abscess to the perinephric space

(iv) Class 3B: extension of the gas or abscess to the pararenal space

(v) Class 4: bilateral EPN or solitary kidney with EPN

Furthermore, Wan et al.'s classification [7] proposed 2 types:

(i) Type I EPN: renal parenchymal with an absence of fluid content or the presence of streaky/mottled gas

(ii) Type II EPN: the presence of renal or perirenal fluid accompanied by a bubbly gas pattern or the presence of gas in the collecting system

Our patient was classified as class 4 and type II EPN of Huang et al. and Wan et al.'s classifications, respectively.

For the initial management of type I EPN, emergent nephrectomy is recommended. However, percutaneous drainage is indicated for the treatment of type II EPN [8].

On the other hand, pneumomediastinum can be primary or spontaneous if the cause is idiopathic or secondary if it is caused by a traumatic or iatrogenic etiology [9]. Dyspnea and chest pain are the most common symptoms [10]. Predisposing factors such as drug abuse, asthma, and chronic obstructive pulmonary disease are proved, with tobacco being the most important [9].

The physiopathology of SP is not fully proven. The SARS-CoV-2 virus infects type II pneumocytes causing alveolar damage, generating interstitial emphysema that could progress to the mediastinal space and subcutaneous emphysema [11] compounded by the increasing pressure difference between the alveolar space and the interstitium [12].

To accelerate the resorption of pneumomediastinum, oxygen therapy, which is not systematic, would cause the absorption of free air by increasing the nitrogen concentrations [13].

The diffuse COVID-19 complicated by a large abundance of SP was associated with a severe clinical course characterized by sudden acute respiratory distress syndrome that required aggressive management and early intubation. Furthermore, the presence of pneumomediastinum required some changes in the management of mechanical ventilation 


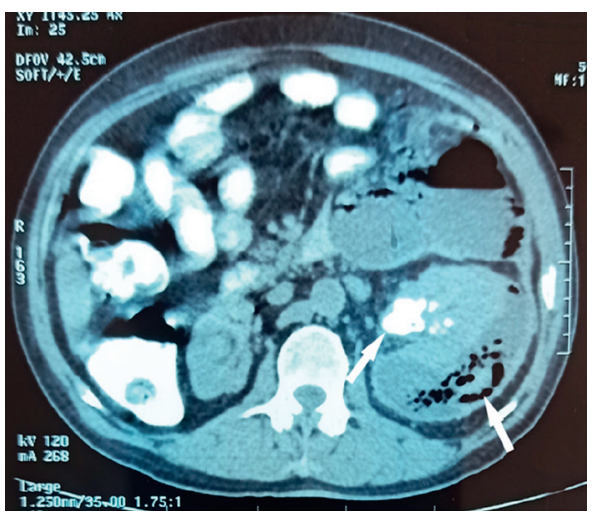

(a)

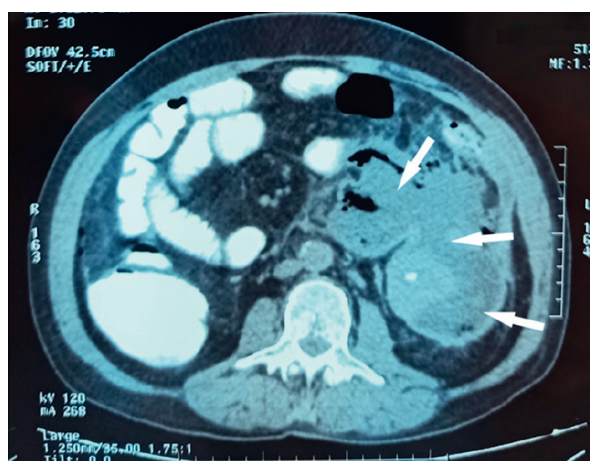

(c)

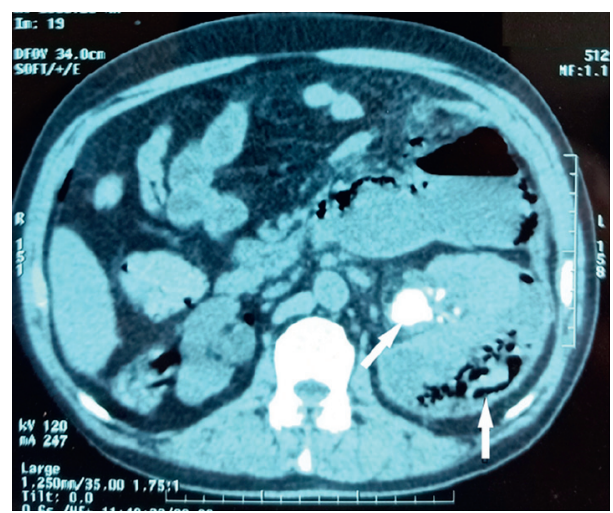

(b)

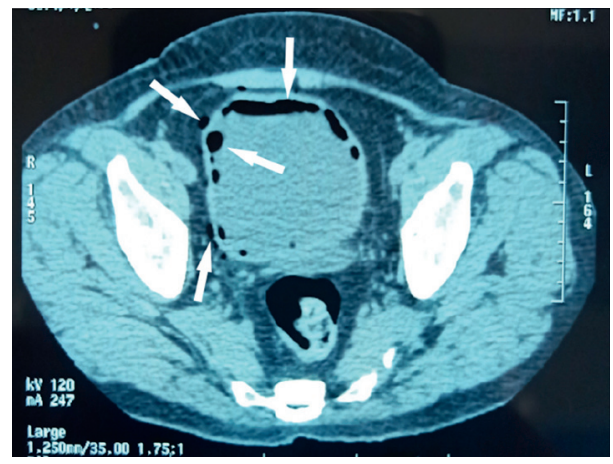

(d)

FIgURE 1: Abdominal CT scan showing ( $\mathrm{a}, \mathrm{b})$ obstructive emphysematous pyelonephritis on a single functional kidney, (c) renal abscess communicating with intraperitoneal collections measuring approximately $208 \times 113 \mathrm{~mm}$ with no passage of intraperitoneal contrast product at high digestive opacification, and (d) emphysematous cystitis.

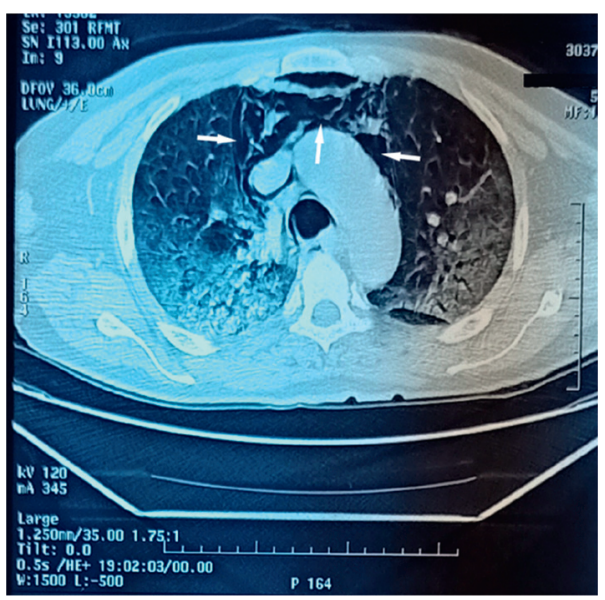

(a)

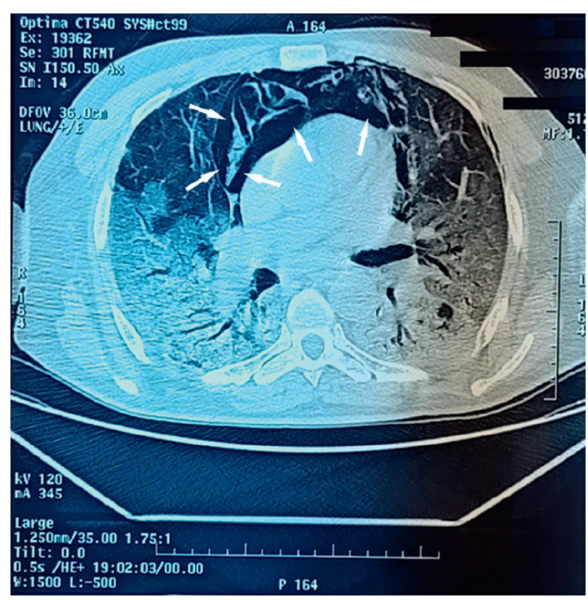

(b)

Figure 2: Continued. 


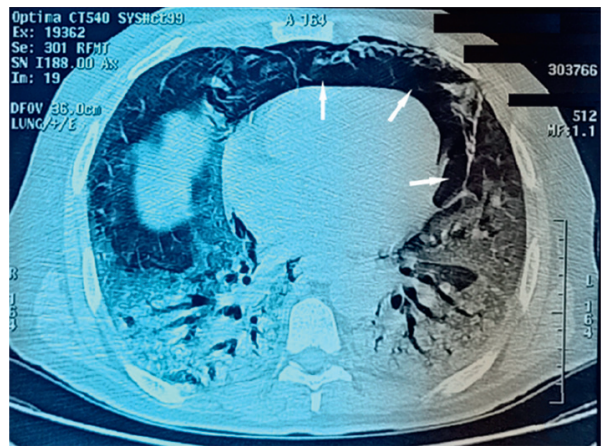

(c)

Figure 2: $(\mathrm{a}, \mathrm{b}, \mathrm{c})$ Chest CT scan showing ground-glass opacities with crazy paving of mixed topography, bilateral to lower predominance with a degree of critical involvement $>75 \%$ classified CORADS 5 and a large abundance of spontaneous pneumomediastinum.

to minimize volutrauma and prevent its expansion. Overventilation should be avoided, measures should be taken to limit hyperinflation, and low positive end-expiratory pressures should be used [14].

The diagnosis of pneumomediastinum in diffuse COVID-19 is associated with a grim prognosis [15].

\section{Conclusions}

This combination of EPN and EC in a patient with diffuse COVID-19 complicated by a large abundance of SP is the first case of its kind. Its management is multidisciplinary. The prognosis of each pathology is already bleak. Their combination is associated with a worse prognosis and fatal outcomes.

\section{Consent}

Consent from the patient has been taken for this case report.

\section{Conflicts of Interest}

None of the contributing authors have any conflicts of interest.

\section{References}

[1] Y.-C. Lu, B.-J. Chiang, Y.-H. Pong et al., "Emphysematous pyelonephritis: clinical characteristics and prognostic factors," International Journal of Urology, vol. 21, no. 3, pp. 277-282, 2014.

[2] M. F. Mnif, M. Kamoun, F. H. Kacem et al., "Complicated urinary tract infections associated with diabetes mellitus: pathogenesis, diagnosis and management," Indian journal of endocrinology and metabolism, vol. 17, no. 3, pp. 442-445, 2013.

[3] A. Schicho, C. Stroszczynski, and P. Wiggermann, "Emphysematous cystitis: mortality, risk factors, and pathogens of a rare disease," Clinics and practice, vol. 7, p. 930, 2017.

[4] Y.-C. Lu, B.-J. Chiang, Y.-H. Pong et al., "Predictors of failure of conservative treatment among patients with emphysematous pyelonephritis," BMC Infectious Diseases, vol. 14, no. 1, p. 418, 2014.

[5] V. Chávez-Valencia, C. Orizaga-de-La-Cruz, O. Aguilar-Bixano, and F. A. Lagunas-Rangel, "Coexistence of emphysematous cystitis and bilateral emphysematous pyelonephritis: a case report and review of the literature," CEN Case Reports, vol. 9, no. 4, pp. 313-317, 2020.

[6] J.-J. Huang and C.-C. Tseng, "Emphysematous pyelonephritis," Archives of Internal Medicine, vol. 160, no. 6, p. 797, 2000.

[7] Y. L. Wan, T. Y. Lee, M. J. Bullard, and C. C. Tsai, "Acute gas-producing bacterial renal infection: correlation between imaging findings and clinical outcome," Radiology, vol. 198, no. 2, pp. 433-438, 1996.

[8] W.-R. Lin, M. Chen, J.-M. Hsu, and C.-H. Wang, "Emphysematous pyelonephritis: patient characteristics and management approach," Urologia Internationalis, vol. 93, no. 1, pp. 29-33, 2014.

[9] S. Sahni, S. Verma, J. Grullon, A. Esquire, P. Patel, and A. Talwar, "Spontaneous pneumomediastinum: time for consensus," North American Journal of Medical Sciences, vol. 5, pp. 460-464, 2013.

[10] W. L. Dajer-Fadel, R. Argüero-Sánchez, C. Ibarra-Pérez, and F. P. Navarro-Reynoso, "Systematic review of spontaneous pneumomediastinum: a survey of 22 years' data," Asian Cardiovascular and Thoracic Annals, vol. 22, no. 8, pp. 997-1002, 2014.

[11] L. E. Gralinski and R. S. Baric, "Molecular pathology of emerging coronavirus infections," The Journal of Pathology, vol. 235, no. 2, pp. 185-195, 2015.

[12] M. Lacroix, F. Graiess, L. Monnier-Cholley, and L. Arrivé, "SARS-CoV-2 pulmonary infection revealed by subcutaneous emphysema and pneumomediastinum," Intensive Care Medicine, vol. 46, no. 8, pp. 1620-1621, 2020.

[13] M. Ebina, A. Inoue, A. Takaba, and K. Ariyoshi, "Management of spontaneous pneumomediastinum: are hospitalization and prophylactic antibiotics needed?" The American Journal of Emergency Medicine, vol. 35, no. 8, pp. 1150-1153, 2017.

[14] V. Mohan and R. A. Tauseen, "Spontaneous pneumomediastinum in COVID-19," BMJ Case Reports, vol. 13, no. 5, Article ID e236519, 2020.

[15] M. Al-Azzawi, S. Douedi, A. Alshami, G. Al-Saoudi, and J. Mikhail, "Spontaneous subcutaneous emphysema and pneumomediastinum in COVID-19 patients: an indicator of poor prognosis?" American Journal of Case Reports, vol. 21, Article ID e925557, 2020. 